\title{
Combined Toxicity of Chlorpyrifos, Abamectin, Imidacloprid, And Acetamiprid On Earthworms (Eisenia Fetida)
}

\section{Miaomiao Teng}

Chinese Research Academy of Environmental Sciences

Xiaoli Zhao ( $\square$ zhaoxiaoli-zxl@126.com )

Chinese Research Academy of Environmental Sciences

Chen Wang

Chinese Research Academy of Environmental Sciences

\section{Lingfeng Zhou}

Chinese Research Academy of Environmental Sciences

\section{Xiaowei Wu}

Chinese Research Academy of Environmental Sciences

\section{Fengchang Wu}

Chinese Research Academy of Environmental Sciences

\section{Research Article}

Keywords: neonicotinoid, chlorpyrifos, abamectin, combined toxicity, earthworm

Posted Date: August 20th, 2021

DOI: https://doi.org/10.21203/rs.3.rs-794675/v1

License: (c) (i) This work is licensed under a Creative Commons Attribution 4.0 International License. Read Full License

Version of Record: A version of this preprint was published at Environmental Science and Pollution Research on March 17th, 2022. See the published version at https://doi.org/10.1007/s11356-021-18025W. 


\section{Abstract}

Mixed pesticides have been broadly used in agriculture. However, assessing the combined effects of pesticides in the environment is essential for potential risk assessment, though the task is far from complete. Median lethal concentrations of pesticides as well as acetylcholinesterase (AChE) levels and cellulose activities were measured in earthworms (Eisenia fetida) individually and jointly exposed to pesticides imidacloprid (IMI), acetamiprid (ACE), chlorpyrifos (CRF), and abamectin (ABM)). A 3:1 mixture of CRF and IMI had additive effects, while a 3:1 mixture of CRF and ACE had synergic effects. The joint effects of ABM with IMI or with ACE were synergistic. As CRF concentration increased, AChE activities were significantly decreased. For high concentrations of IMI, AChE activities under combined CRF and IMI applications were significantly inhibited following increased exposure time. Moreover, the cellulase activities under combined applications of CRF with IMI or with ACE had similar effects. This study provides basic data for scientifically evaluating the environmental risk and safety of combined uses of pesticides.

\section{Introduction}

The use of pesticides in the agricultural industry has continuously increased. In 2017, the total amount of pesticides employed in agriculture use was more than 4.1 million tons (Food and Agriculture Organization of the United Nations (FAO)). The wide use of pesticides and their potential effects upon entering into environments and subsequent hazards on the balance of ecosystems are drawing more attention (Bishop et al. 2020, Fang et al. 2019, Utami et al. 2020). Thorough knowledge of biochemical responses and combined effects of pesticides in the environment is essential for proper risk assessment (Sakthiselvi et al. 2020, Zhou et al. 2020).

Neonicotinoid pesticides are one of the most commonly used classes of insecticides and affect nicotinic acetylcholine receptors to influence insects' nervous systems, ultimately resulting in their paralysis and death. Because of their efficient insecticidal activity and low toxicity to vertebrates and most invertebrates, neonicotinoids are widely used in crop applications, seed treatment, soil, and control of pests on household pets, underlying the world-leading sales of this class of pesticides among all others (Cimino et al. 2017, Douglas \&Tooker 2015). In China, 8000 tons of acetamiprid (ACE) and 14,000 tons of imidacloprid (IMI) are used every year (Xusheng et al. 2013). Owning to their high solubility and relatively low degradation in soil, water, and other chemical reagents, the environmental and health effects of neonicotinoids have gained research attention. In recent years, the negative effects of neonicotinoids in organisms have been studied, including their associated underlying risk to human health (Hallmann et al. 2014). Neonicotinoids have been reported to reduce the reproduction of bees and increase their mortality via inhibiting their homing ability (Rundlof et al. 2015, Stanley et al. 2015, Woodcock et al. 2017). A previous study showed that serum concentrations of IMI and ACE are 0.65 and $0.06 \mu \mathrm{g} / \mathrm{L}$, respectively, in people over sixty years old in Saudi Arabia (Li et al. 2020). The metabolism and dissipation of IMI and ACE are relatively safe. However, differences in environmental conditions, microbial activity, and soil properties influence IMI and ACE dissipation in soil (Castillo Diaz et al. 2016, Xu et al. 2020). Additionally, 
neonicotinoid insecticides are assimilated by plants and transported to organs, including roots, thus contaminating soil and under-ground organisms. It is crucial to understand the impact of IMI and ACE on the soil organisms to enable proper risk assessment and safety.

Chlorpyrifos (CRF) is a typical organophosphorus pesticide and neurotoxic insecticide, as an acetylcholinesterase inhibitor that overstimulates the nervous system. It is extensively applied to seeds, lawns, and crops. In particular, the total production of CRF exceeds 200,000 tons, with rates of use increasing by $10 \%$ annually in China (John \&Shaike 2015). However, CRF contamination has aroused the concerns of researchers since 1989. Previous studies have reported that CRF increased the population of fungi and the number of bacteria, while decreasing nitrogen fixation and microorganism levels in soil (John \&Shaike 2015, Pandey \&Singh 2004, Singh et al. 2015). In addition, in 2019, CRF was noted to have potential developmental toxicity, neurotoxicity, and genotoxicity, which increased attention on its human health impacts by the European Food Safety Authority (EFSA)((FSN) 2019). Thus, reasonable and efficient risk assessment of CRF could help farmers to use this pesticide safely.

ABM is generated by actinomycete fungi (Streptomyces avermitilis), belonging to the family of avermectins, and it is used to eliminate nasal bots, gastrointestinal nematodes and lung worms in sheep and cattle (Campbell 2012). ABM is a mixture containing less than $20 \%$ avermectin $B_{1 b}$ and more than $80 \%$ avermectin $B_{1 a}$. It interferes with neurophysiological activities and stimulates the release of $y$-amino butyric acid (GABA), which has an inhibitory effect on the nerve conduction of arthropods, resulting in their paralysis, and death. ABM is slightly solubility in water and has a lipophilic character that makes it difficult for mammals to metabolize, $80-98 \%$ of the chemical dose is eliminated in stools and transferred to soil (Sun et al. 2005). It is essential to evaluate the toxicities of ABM using soil organisms.

The global population of earthworms has decreased gradually owing to threats of environmental pollutants, habitat loss and reductions of microbial communities. Earthworms (Eisenia fetida) are the most populous terrestrial soil animal species. They have a critical role in breaking down organic matter and thus contribute to soil fertility and soil formation (Mattsson et al. 2017). Earthworms inhabit moist soil, where they come in contact with pesticides via inhalation, swallowing soil, gut absorbing and skin contact. In recent decades, earthworms have been used as a typical model of invertebrate species in soil toxicology studies. They have been selected for research because they are easy to culture in laboratory settings, have a high reproduction rate, short life cycle, and small body size, and can be used as bioindicators of soil pollutants. However, earthworms are sensitive to environmental contaminants. Despite the abundance of earthworms, their population size and diversity have both declined. The wide use of pesticides could be a serious threat to earthworm survival. Therefore, earthworms are suitable for the toxicological assessment of environmental pollutants.

Despite IMI, ACE, CRF, and ABM having different modes of action, their applications all induce severe damage to soils (Hasenbein et al. 2015, Wang et al. 2015b). Pesticides may disturb soil ecosystems and impact soil invertebrate structure (Yang et al. 2018). As a result, the wide use of insecticides is being questioned on environmental grounds in a number of countries, leading to usage restrictions. However, in 
spite of growing research efforts to understand insecticide use and its potential effects on a variety of organisms, we still lack assessments of the combined effects of insecticide pollutants in the environments, especially in soil, in order to evaluate their potential risks to underground organisms. To fill such a knowledge gap, we measured the individual and joint toxic effects of IMI, ACE, CRF, and ABM on earthworms, including effects on the activities of acetylcholinesterase (AChE) and cellulase. AChE is the target enzyme for pest control by insecticides, such as neonicotinoids and organophosphate pesticides. In earthworms, cellulase activity indicates relatively high activities of endoglucanase more broadly (Ikarashi et al. 2016).

In order to assess the toxic effects of pesticides to earthworms, artificial soil test protocols have been used (OECD 1984, 2004). Artificial soil tests simulate the natural environment of earthworms. In this type of assay, earthworms absorb pollutants through their guts (Brami et al. 2017). Many studies could use this approach to more efficiently assess the toxicities of contaminants to earthworms.

\section{Methods And Materials}

\section{Chemicals and reagents}

The following chemicals were obtained for the present study: ABM (95.75\% purity; from Shanxi Xi'an Meibang Pesticide Co., Ltd., Xi'an, China), IMI [(2E)-1-((6-chloro-3-pyridinyl)methyl)-N-nitro-2imidazolidinimine] (97.6\% active ingredients, from Zhejiang Haizheng Pesticide Company, Taizhou, China), CRF (97\% purity, from Sumitomo Chemical Corp., Tokyo, Japan), ACE (96\% active ingredients, from Beijing Huarong Pesticide Company, Beijing, China). The four pesticides were dissolved in acetone to a $1 \times 10^{4} \mathrm{mg} / \mathrm{L}$ concentration and stored at $4{ }^{\circ} \mathrm{C}$. All other reagents used were of analytical grade.

\section{Earthworm acute toxicity test}

Earthworms (Eisenia fetida) were obtained from the College of Resources and Environmental Sciences, China Agricultural University, Beijing, China. The artificial soil used for the testing was comprised of $70 \%$ quartz sand, $20 \%$ kaolin clay, $10 \%$ sphagnum peat, and calcium carbonate to regulate the $\mathrm{pH}$ to $6.5 \pm$ 0.5 (OECD 1984). After acclimation for one week in an environmental chamber maintained at $20 \pm 0.5^{\circ} \mathrm{C}$, $80 \pm 2 \%$ humidity, and 400-800 lux illumination. 2-month-old earthworms with well-developed clitella $(0.30-0.45 \mathrm{~g})$ were selected randomly and deprived of food for $4 \mathrm{~h}$ before the experiment was conducted. The soil was prepared by adding different concentrations ( $\mathrm{mg} / \mathrm{kg}$, dry soil) of pesticides (CRF, ABM, IMI, ACE, and their mixtures). The preferred amounts of pesticide were carefully mixed into soil as an aqueous solution to yield the working concentrations of pesticides, and mixed soils were transferred into glass jars. Ten adult earthworms were placed into 1-L glass containers filled with test substrate, and test containers were enclosed with a polythene sheet with integrated gauze $(+1 \mathrm{~mm})$ to prevent the worms from escaping and to ensure optimal ventilation. After 1, 7, and $14 \mathrm{~d}$ of incubation, living worms were sorted by hand, and the test endpoint was mortality. Three replicates were conducted for acute toxicity tests. In parallel, solvent and control treatments were also conducted with three replicates. 


\section{Earthworm sample collection and AChE assay}

According to the lethal concentration results, different concentrations of pesticides were designated for testing the biochemical response of insecticides on AChE activity. The AChE enzyme activity was assayed in triplicate (10 worms/ replicate) if the given treatment did not induce a significant death at 1, 3, 7,14 , and $21 \mathrm{~d}$. Daily observations were recorded. Live earthworms were depurated for $4 \mathrm{~h}$ on moist filter paper to empty their gut contents, rinsed, and then stored at $-80^{\circ} \mathrm{C}$ for further study.

The AChE activity was determined according to a previously described method (Worek et al. 2012). The total protein contents were measured according to the manufacturer's protocol (Bradford method, Beyotime Biotechnology, Shanghai, China). Earthworm samples were homogenized in phosphate buffer $(\mathrm{pH}=7.4 ; 1 / 4, w / v)$ and centrifuged at $8000 \times g, 4{ }^{\circ} \mathrm{C}$ for $15 \mathrm{~min}$. Then, $50 \mu \mathrm{L}$ of supernatant was combined with $150 \mu \mathrm{L}$ of mixture containing $1.5 \mathrm{~mL}$ of $10 \mathrm{mM}$ acetylthiocholine iodide and $1.2 \mathrm{~mL}$ of 6.2 $\mathrm{mM} 5.5^{\prime}$-dithiobis-2-nitrobenzoic acid in $30 \mathrm{~mL}$ of $100 \mathrm{mM}$ phosphate buffer. Absorbance was read at 405 $\mathrm{nm}$ after $15 \mathrm{~min}$.

\section{Cellulase activity assay.}

Earthworms were collected following exposure to pesticides for 1, 7, and $14 \mathrm{~d}$. After a 4-h gut cleaning period, two earthworms from each treatment were randomly selected for homogenization with ice-cold phosphate buffer. Cellulase activity was measured using the carboxymethyl cellulose (CMC) method as described by Ghose (Ghose \&T. 1987).

\section{Statistical analysis}

Mortality and biochemical results were determined by one-way analysis of variance (ANOVA) using SPSS 16.0 software (SPSS Inc., Chicago, IL, USA). The median lethal concentrations of chemicals $\left(L_{50}\right)$ and associated $95 \%$ confidence limits were calculated by probit analysis. Significant differences were analyzed by using Dunnett's test, and a $P<0.05$ threshold was applied to identify significant results.

The co-toxicity coefficient of pesticides was calculated using the Sun method with the following equations (Sun \&Johnson 1960).

single toxic index $(\mathrm{TI})=$ standard reagent $\mathrm{LC}_{50} \times 100 /$ test reagent $\mathrm{LC}_{50}$

mixture actual toxic index $(A T I)=$ standard reagent $L_{50} \times 100 /$ mixture reagents $L_{50}$

theoretical toxic index $(\mathrm{TTI})=\mathrm{ATI} \times \mathrm{A} \%+\mathrm{BTI} \times \mathrm{B} \%+\mathrm{CTI} \times \mathrm{C} \%+\ldots \ldots$

co-toxic coefficients $=$ ATI $\times 100 /$ TTI

\section{Results}




\section{Lethal effect of pesticides}

Table 1 The acute toxicity of pesticides on earthworms (14-d artificial soil test results)

\begin{tabular}{ccccc}
\hline & $\begin{array}{c}\text { Regression } \\
\text { equation }\end{array}$ & $\mathrm{LC}_{50}(\mathrm{mg} / \mathrm{kg})$ & $\begin{array}{c}\text { Confidence } \\
\text { iterval }\end{array}$ & CTC \\
Ratio of pesticides & $\mathrm{Y}=-18.2+8.6 \mathrm{x}$ & $1.31 \times 10^{2}$ & $1.19 \sim 1.43$ & - \\
\hline CRF & $\mathrm{Y}=-3.12+6.63 \mathrm{x}$ & 2.96 & $2.57 \sim 3.40$ & - \\
IMI & $\mathrm{Y}=-4.12+9.59 \mathrm{x}$ & 2.69 & $2.54 \sim 2.85$ & - \\
ACE & $\mathrm{Y}=-5.08+5.16 \mathrm{x}$ & 9.68 & $7.06 \sim 11.32$ & - \\
ABM & $\mathrm{Y}=-2.5+2.5 \mathrm{x}$ & 10.7 & $8.1 \sim 19.3$ & 104 \\
$\mathrm{CRF}:$ IMI $(3: 1)$ & $\mathrm{Y}=-13.5+10.8 \mathrm{x}$ & 17.6 & $16.6 \sim 18.8$ & 103 \\
$\mathrm{CRF}:$ IMI $(6: 1)$ & $\mathrm{Y}=-11.5+8.1$ & 26.4 & $24.2 \sim 28.8$ & 93 \\
$\mathrm{CRF}:$ IMI $(9: 1)$ & $\mathrm{Y}=-2.38+4.10 \mathrm{x}$ & 3.79 & $3.19 \sim 4.52$ & 268 \\
$\mathrm{CRF}:$ ACE $(3: 1)$ & $\mathrm{Y}=-3.2+3.2 \mathrm{x}$ & 10.2 & $8.3 \sim 13.3$ & 164 \\
$\mathrm{CRF}:$ ACE $(6: 1)$ & $\mathrm{Y}=-4.3+4.3 \mathrm{x}$ & 10.1 & $8.5 \sim 12.3$ & 225 \\
$\mathrm{CRF}:$ ACE $(9: 1)$ & $\mathrm{Y}=-3.19+7.79 \mathrm{x}$ & 2.57 & $2.25 \sim 2.92$ & 140 \\
$\mathrm{ABM}:$ IMI $(1: 3)$ & $\mathrm{Y}=-0.889+4.18 \mathrm{x}$ & 1.63 & $0.636 \sim 6.14$ & 201 \\
$\mathrm{ABM}:$ ACE $(1: 3)$ & & & &
\end{tabular}

The $\mathrm{LC}_{50}$ results for earthworms after 14-d pesticide exposures are shown in Table 1. Different pesticides have different lethal effects on earthworms. The pesticides can be arranged in descending order of lethal sensitivity to earthworms as follows: ACE $(2.69 \mathrm{mg} / \mathrm{kg})$, IMI $(2.96 \mathrm{mg} / \mathrm{kg})$, ABM $(9.68 \mathrm{mg} / \mathrm{kg})$, CRF $\left(1.31 \times 10^{2} \mathrm{mg} / \mathrm{kg}\right)$. The lethal effect of CRF was relatively lower than that of other pesticides. We then measured the acute toxicity of different ratios of pesticides to clarify the interplay between neonicotinoids and each pesticide, as well as their $\mathrm{LC}_{50}$ values for earthworms. The mixture toxicities for 3:1, 6:1, and 9:1 ratios of mixtures of CRF and IMI were 10.7, 17.6, and $26.4 \mathrm{mg} / \mathrm{kg}$, respectively. The response to a mixture of CRF and IMI was additive. Additionally, 3:1, 6:1, and 9:1 ratios of mixtures of CRF and ACE were $3.79,10.2$, and $10.1 \mathrm{mg} / \mathrm{kg}$, respectively. CTC values ranged from 164 to $268 \mathrm{mg} / \mathrm{kg}$. For the other two mixtures, the 14-day $\mathrm{LC}_{50}$ of 1:3 mixtures of ABM with IMI and ACE were 2.565 and $1.632 \mathrm{mg} / \mathrm{kg}$, respectively, indicating synergistic responses.

IMI and ACE are neonicotinoids with similar chemical structures, though they differ in their acute toxicity after being combined with CRF. The joint toxicity of CRF and IMI is additive, while CRF and ACE have a synergistic response. Owing to the complexity of the joint toxicity of insecticides to earthworms, CRF and these two neonicotinoids were selected for subsequent biochemical analyses.

\section{Effects on AChE activity}


The activities of AChE under IMI exposure are presented in Fig. 1A. After a 1-d exposure, IMI-treatments inhibited AChE activity, with higher concentrations of IMI causing significant decreases in AChE enzymatic activities compared to the control group. The AChE activity under $0.0500 \mathrm{mg} / \mathrm{kg}$ IMI treatment led to significant increases following exposure for $3 \mathrm{~d}$, while $0.100 \mathrm{mg} / \mathrm{kg}$ IMI treatment significantly decreased AChE activity. At $7 \mathrm{~d}$, the enzyme activity was significant inhibited in the $0.4000 \mathrm{mg} / \mathrm{kg}$ group. However, after a 21-d exposure, for the lower concentration groups ( 0.0125 and $0.0500 \mathrm{mg} / \mathrm{kg})$, IMI caused significant increases in AChE activity. Similarly, $1.0000 \mathrm{mg} / \mathrm{kg} \mathrm{IMI} \mathrm{significantly} \mathrm{increased} \mathrm{AChE}$ activity in earthworms.

The changes in AChE activities under ACE exposure are summarized in Fig. 1B. The highest concentration of ACE induced a significant increase in AChE activity after a 1-d exposure. After a 3-d exposure, 0.0125 $\mathrm{mg} / \mathrm{kg}$ ACE significantly inhibited AChE activity, but significantly increased its activity under the 0.8000 $\mathrm{mg} / \mathrm{kg}$ treatment. Unexpectedly, there was no significant change in AChE activity following exposure ACE for $7 \mathrm{~d}$. AChE activity was lowered to the control level in earthworms exposed to $0.4000 \mathrm{mg} / \mathrm{kg} \mathrm{ACE}$ for 14 days. At a low pesticide dose, $0.0500 \mathrm{mg} / \mathrm{kg}$ ACE caused a significant increase in AChE activity following a 21- $d$ exposure, while AChE activities were significantly inhibited in earthworms exposed to 0.4000 and $0.8000 \mathrm{mg} / \mathrm{kg}$ ACE.

The effects on earthworm AChE activity induced by CRF are summarized in Fig. 1C. After exposures of 1, $3,7,14$, and $21 \mathrm{~d}, 5 \mathrm{mg} / \mathrm{kg}$ CRF induced significant increases in AChE activity. However, the AChE activities were significantly reduced under the $40 \mathrm{mg} / \mathrm{kg}$ CRF treatment following exposures of $1,3,7$, and $14 \mathrm{~d}$, but not $21 \mathrm{~d}$. After a 7-d exposure, 10 and $30 \mathrm{mg} / \mathrm{kg}$ CRF treatments significantly increased AChE activity. The AChE activity under the $30 \mathrm{mg} / \mathrm{kg} \mathrm{CRF}$ treatment for $14 \mathrm{~d}$ was inhibited. The $10 \mathrm{mg} / \mathrm{kg}$ CRF concentration caused marked increases under a 21-d exposure. AChE activity under CRF and IMI combined at a 3: 1 ratio is summarized in Fig. 2A. The AChE activity under combined pollutant after a 1-d exposure was significantly increased in the $0.800 \mathrm{mg} / \mathrm{kg}$ treatment, but inhibited in $1.000 \mathrm{mg} / \mathrm{kg}$ group. There were significant increases in the AChE activities of earthworms following exposure to the combined application of CRF and IMI after $3 \mathrm{~d}$. AChE activity was significant increased after a 7-d exposure to the combinations in the $0.800 \mathrm{mg} / \mathrm{kg}$ treatment groups. Unexpectedly, the combined pollutants did not result in significant changes in AChE activities at any exposure concentration for 14 and $21 \mathrm{~d}$. The joint toxicity on AChE activity of CRF and ACE combined at a ratio of 3:1 is summarized in Fig. 2B. The AChE activity of the combined application was markedly increased under the $0.050 \mathrm{mg} / \mathrm{kg}$ exposure at $3 \mathrm{~d}$. The $21-\mathrm{d}$ combined exposure was the most sensitive stage among all treatment periods. In the $0.200 \mathrm{mg} / \mathrm{kg}$ coexposure group, the AChE activity was significantly increased, while the combined applications at 0.800 and $1.000 \mathrm{mg} / \mathrm{kg}$ significantly inhibited the activity of AChE.

\section{Effects on cellulase activity}

Pesticides were observed to affect cellulase activity in earthworms (Fig. 3, 4). After 1- and 7- d IMI exposures, cellulase activities were significantly increased except in the $0.4000 \mathrm{mg} / \mathrm{kg}$ treatment group (Fig. 3A). After a 1-d exposure, ACE induced a higher cellulase activity level than the control group. In 
contrast, ACE induced lower cellulase activity. The activity of cellulase significantly increased following exposure to $0.4000 \mathrm{mg} / \mathrm{kg}$ ACE for $14 \mathrm{~d}$ (Fig. 3B). Similarly, after exposure to CRF for $1 \mathrm{~d}$, the cellulase activities significantly increased, expect for the $30 \mathrm{mg} / \mathrm{kg}$ treatment (Fig. 3C). However, 10, 20, and 30 $\mathrm{mg} / \mathrm{kg}$ CRF treatments induced lower cellulase activities than the control at $7 \mathrm{~d}$. We determined the cellulase activities of a 3:1 mixture of CRF and IMI (Fig. 4A). The combined application of CRF and IMI significantly increased the cellulase activity in earthworms following 0.40 and $0.80 \mathrm{mg} / \mathrm{kg}$ treatments for $1 \mathrm{~d}$, but significantly decreased the cellulase activity after 0.05 and $0.10 \mathrm{mg} / \mathrm{kg}$ treatments for $7 \mathrm{~d}$. The cellulase activities in earthworms were significantly increased after 1 and 14-d exposures to the 3:1 mixture of CRF and ACE (Fig. 4B) compared to the control and were inhibited by $0.05,0.40$, and 0.80 $\mathrm{mg} / \mathrm{kg}$ treatments at $7 \mathrm{~d}$.

\section{Discussion}

Nowadays, applications of pesticide mixtures have become a major trend in pesticide use, as combinations of pesticides can expand the scope of use, improve efficiency, reduce the number of resistant pests, and also helping to control and prevent insects more generally. The combined application of pesticides is extensive, and while many studies have been conducted on the joint action mechanism of target organisms, few have examined the effects of combined pesticides in non-target organisms.

Our CRF, IMI, ACE, and ABM toxicity results from the present study match the range of $\mathrm{LC}_{50}$ values described by previous studies conducted in the earthworms (Eisenia fetida) (Dong-Mei et al. 2015, Karanjkar \&Naik 2009, Tenorio Nunes \&Gaeta Espindola 2012, Wang et al. 2015a). However, the LC $_{50}$ value for IMI in the European earthworms (E. Andrei, Lumbricidae) was $25.53 \mathrm{mg} / \mathrm{kg}$, which is a discrepancy that can be interpreted as two different species having different responses to this chemical (Alves et al. 2013). The sensitivity of earthworms to pesticides in assays with natural soil and artificial substrate also present different values (Bandeira et al. 2020, Tenorio Nunes \&Gaeta Espindola 2012).

Two-pesticide combinations (i.e., CRF and ACE, ABM and IMI, and ABM and ACE) exhibited synergistic effects in the present soil toxicity test. Synergistic responses may impair soil organisms (such as earthworms), hindering their survival in their natural environments (Uwizeyimana et al. 2017). If one pollutants in the combined application triggers changes in the toxicity kinetics of an organism, then synergistic interactions may be observed in combinations including that pollutant (Rizzati et al. 2016). Synergistic responses can be affected by the co-occurrence of avermectin and neonicotinoid pesticides. However, direct evidence of target enzyme alterations needs to be investigated in the future studies.

The main function of $\mathrm{AChE}$ is to stop pulse transmission in the cholinergic synapse by rapidly hydrolyzing the neurotransmitter acetylcholine. Many studies have shown that the target of CRF and neonicotinoid pesticides is related to acetylcholinesterase (Rao et al. 2003, Reinecke \&Reinecke 2007, Shao et al. 2013). CRF, as a cholinesterase inhibitor mainly inhibits AChE, causing neurological dysfunction and thus affecting neurodevelopment (John \&Shaike 2015). In the current study, the AChE activities were gradually inhibited in earthworms as CRF concentrations increased. The targets of 
neonicotinoid pesticides are the nicotinic acetylcholine receptors (nAChRs) of the postsynaptic membrane, a member of the family of ligand-gated ion channels, at the center of insects (Shao et al. 2013). The hydrolysis of acetylcholine is catalyzed by the AChE, which is a crucial enzyme in the development and functions of nervous systems (Colovic et al. 2013). Additionally, the nervous system plays an important role in neurotransmission (Kaizer et al. 2017). In high-concentration of IMI treatments, the AChE activities of combined CRF and IMI application decreased significantly as exposure time increased. A decrease in AChE increases levels of the neurotransmitter acetylcholine, which then induces the over-stimulation of muscles overall and finally causes insects paralysis and death. Thus, changes in AChE activity could have toxic effects in earthworms.

However, the joint AChE activities under CRF and ACE are complex. For example, as ACE concentration increased, AChE activity gradually increased after a 1- and 7- $d$ exposure, but its activity decreased significantly as concentrations increased. There was a difference between the two combined applications likely owing to the structure of ACE and IMI. CRF binds with monooxygenase to activate the molecules to varying degrees, resulting in alteration of the AChE activity (Belden \&Brain 2017).

Cellulase is a cold-tolerant digestive enzyme that is involved in cellulose digestion (Ikarashi et al. 2016). Notably, cellulase plays a major role in gut epithelial cells. In an artificial soil test, the gut absorbs environmental pollutants under controlled conditions (Nozaki et al. 2009). Increases in cellulase activity were induced by IMI and ACE exposures of $1 \mathrm{~d}$ and recovered to normal levels at $14 \mathrm{~d}$. The recovery period for cellulase in these assays was longer than that for the CRF exposure. However, the cellulase activities in the combined applications of CRF with IMI and ACE was similar. On the first day, cellulase was activated by the two combined applications, while the enzyme returned to normal levels after a 7-d exposure. Insecticides are assimilated by earthworms at their initial exposure and stimulated increased cellulase activity, which then accelerated digestion, a known stress response. By 7 or $14 \mathrm{~d}$, pesticides were metabolized and cellulase activities recovered.

\section{Conclusion}

The development and application of mixtures of pesticides in China and elsewhere are extensive, and there are many studies on the combined action mechanism on target organisms. The screening of compound formulas and the determination of co-toxicity coefficients are necessary for assessing the effects of compound preparations. This study has focused on whether the combined effects of the compound preparations have effects on a critcal soil organism, i.e., earthworms, and provides a basis for environmental risk assessment and the rational use of these compound pesticides.

\section{Declarations}

\section{Availability of data and materials}


The datasets used and/or analyzed during the current study are available from the corresponding author on reasonable request.

\section{Authors' contributions}

Miaomiao Teng: Investigation; formal analysis; validation; writing original draft.

Xiaoli Zhao: Conceptualization; investigation; supervision; resources; writing, review \& editing.

Chen Wang: Conceptualization; writing, review and editing.

Lingfeng Zhou: Investigation; formal analysis.

Xiaowei Wu: review and editing.

Fengchang Wu: Resources; writing-review and editing, project administration;

\section{Funding}

This work was supported by the National Natural Science Foundation of China [grant number 41630645, 41521003].

Ethics approval and consent to participate: Not applicable

Consent for publication: Not applicable

Competing interests: The authors declare that there is no competing financial interest.

\section{References}

1. (FSN) FSN (2019) European votes against renew. Chlorpyrifos approval. https://www.foodsafetynews.com/2019/12/eu-votes-against-renewing-chlorpyrifos-approval/

2. Alves PRL, Cardoso EJBN, Martines AM, Sousa JP, Pasini A (2013) Earthworm ecotoxicological assessments of pesticides used to treat seeds under tropical conditions. Chemosphere 90:26742682

3. Bandeira FO, Alves PRL, Hennig TB, Schiehl A, Cardoso EJBN, Baretta D (2020) Toxicity of imidacloprid to the earthworm Eisenia andrei and collembolan Folsomia candida in three contrasting tropical soils. J Soils Sediments 20:1997-2007

4. Belden JB, Brain RA (2017) Incorporating the joint toxicity of co-applied pesticides into the ecological risk assessment process. Integrated Environmental Assessment \& Management

5. Bishop CA, Woundneh MB, Maisonneuve F, Common J, Elliott JE, Moran AJ (2020) Determination of neonicotinoids and butenolide residues in avian and insect pollinators and their ambient environment in Western Canada $(2017,2018)$. Science of the Total Environment 737 
6. Brami C, Glover AR, Butt KR, Lowe CN (2017) Avoidance, biomass and survival response of soil dwelling (endogeic) earthworms to OECD artificial soil: potential implications for earthworm ecotoxicology

7. Campbell WC (2012) Ivermectin and abamectin. Springer Science \& Business Media

8. Castillo Diaz JM, Martin-Laurent F, Beguet J, Nogales R, Romero E (2016) Fate and effect of imidacloprid on vermicompost-amended soils under dissimilar conditions: Risk for soil functions, structure, and bacterial abundance. ence of the Total Environment 579:1111-1119

9. Cimino AM, Boyles AL, Thayer KA, Perry MJ (2017) Effects of Neonicotinoid Pesticide Exposure on Human Health: A Systematic Review. Environ Health Perspect 125:155-162

10. Colovic MB, Krstic DZ, Lazarevic-Pasti TD, Bondzic AM, Vasic VM (2013) Acetylcholinesterase Inhibitors: Pharmacology and Toxicology. Current Neuropharmacology

11. Dong-Mei XU, Yan-Hua W, Nan W, Gui-Wei R (2015) Effects of Single and Co-Exposure of Cu and Chlorpyrifos on the Toxicity of Earthworm. Environmental Science 36:280-285

12. Douglas MR, Tooker JF (2015) Large-Scale Deployment of Seed Treatments Has Driven Rapid Increase in Use of Neonicotinoid Insecticides and Preemptive Pest Management in U.S. Field Crops, 49. Environmental ence \& Technology, pp 5088-5097

13. Fang W, Peng Y, Muir D, Lin J, Zhang X (2019) A critical review of synthetic chemicals in surface waters of the US, the EU and China. Environment international 131:104994

14. Food and Agriculture Organization of the United Nations (FAO) F http://www.fao.org/faostat/en.\#data/RP

15. Ghose TK (1987) Measurement of cellulase activities. Pure \& Applied, Chemistry 59

16. Hallmann CA, Foppen RPB, Turnhout CAMV, Kroon HD, Jongejans E (2014) Declines in insectivorous birds are associated with high neonicotinoid concentrations. Nature 511:341-343

17. Hasenbein S, Lawler SP, Geist J, Connon RE (2015) The use of growth and behavioral endpoints to assess the effects of pesticide mixtures upon aquatic organisms. Ecotoxicology

18. Ikarashi Y, Yarimizu J, Yokoyama K, Kobayashi T, Nakazawa H (2016) Characterization of two endoglucanases for the classification of the earthworm, Eisenia fetida Waki. Bioscience Biotechnology \& Biochemistry

19. John EM, Shaike JM (2015) Chlorpyrifos: pollution and remediation. Environ Chem Lett 13:269-291

20. Kaizer RR, Spanevello RM, Costa E, Morsch VM, Schetinger MRC (2017) Effect of high fat diets on 5'nucleotidase and acetylcholinesterase activities in the central nervous system. International Journal of Developmental Neuroence the Official Journal of the International Society for Developmental Neuroence, S0736574817300096

21. Karanjkar AS, Naik RL (2009) Acute toxicity: novel mode of pesticides on earthworm. International Journal of Plant Protection 2:182-185

22. Li AJ, Banjabi AA, Takazawa M, Kumosani TA, Yousef JM, Kannan K (2020) Serum concentrations of pesticides including organophosphates, pyrethroids and neonicotinoids in a population with 
osteoarthritis in Saudi Arabia. Science of The Total Environment 737:139706

23. Mattsson K, Johnson EV, Malmendal A, Linse S, Hansson LA, Cedervall T (2017) Brain damage and behavioural disorders in fish induced by plastic nanoparticles delivered through the food chain. Science Reports 7:11452

24. Nozaki M, Miura C, Tozawa Y, Miura T (2009) The contribution of endogenous cellulase to the cellulose digestion in the gut of earthworm (Pheretima hilgendorfi: Megascolecidae). Soil Biol Biochem 41:762-769

25. OECD P, France (1984) Earthworm Acute Toxicity. OECD Giideline for Testig of Chemicals No. 207

26. OECD P, France (2004) Earthworm Reproduction Test (Eisenia fetida/Eisenia andrei). OECD Giideline for Testig of Chemicals No. 222

27. Pandey S, Singh DK (2004) Total bacterial and fungal population after chlorpyrifos and quinalphos treatments in groundnut (Arachis hypogaea L.) soil. Chemosphere 55:197-205

28. Rao JV, Pavan YS, Madhavendra SS (2003) Toxic effects of chlorpyrifos on morphology and acetylcholinesterase activity in the earthworm, Eisenia foetida. Ecotoxicol Environ Saf 54:296-301

29. Reinecke SA, Reinecke AJ (2007) The impact of organophosphate pesticides in orchards on earthworms in the Western Cape, South Africa. Ecotoxicology Environmental Safety 66:0-251

30. Rizzati V, Briand O, Guillou H, Gamet-Payrastre L (2016) Effects of pesticide mixtures in human and animal models: An update of the recent literature. Chemico-Biol Interact 254:231-246

31. Rundlof M, Andersson GKS, Bommarco R, Fries I, Hederstrom V, Herbertsson L, Jonsson O, Klatt BK, Pedersen TR, Yourstone J, Smith HG (2015) Seed coating with a neonicotinoid insecticide negatively affects wild bees. Nature 521:77-162

32. Sakthiselvi T, Paramasivam M, Vasanthi D, Bhuvaneswari K (2020) Persistence, dietary and ecological risk assessment of indoxacarb residue in/on tomato and soil using GC-MS. Food Chemistry 328

33. Shao X, Xia S, Durkin, Kathleen A, Casida JE (2013) Insect nicotinic receptor interactions in vivo with neonicotinoid, organophosphorus, and methylcarbamate insecticides and a synergist. Proceedings of the National Academy of Sciences of the United States of America

34. Singh S, Gupta R, Sharma S (2015) Effects of chemical and biological pesticides on plant growth parameters and rhizospheric bacterial community structure in Vigna radiata. J Hazard Mater 291:102-110

35. Stanley DA, Garratt MPD, Wickens JB, Wickens VJ, Potts SG, Raine NE (2015) Neonicotinoid pesticide exposure impairs crop pollination services provided by bumblebees. Nature 528:548-548+

36. Sun Y, Johnson ER (1960) Analysis of Joint Action of Insecticides Against House Flies. J Econ Entomol 53:887-892

37. Sun Y, Diao X, Zhang Q, Shen J (2005) Bioaccumulation and elimination of avermectin B1a in the earthworms (Eisenia fetida). Chemosphere 60:699-704 
38. Tenorio Nunes ME, Gaeta Espindola EL (2012) Sensitivity of Eisenia andrei (Annelida, Oligochaeta) to a commercial formulation of abamectin in avoidance tests with artificial substrate and natural soil under tropical conditions. Ecotoxicology 21:1063-1071

39. Utami RR, Geerling GW, Salami IRS, Notodarmojo S, Ragas AMJ (2020) Environmental prioritization of pesticide in the Upper Citarum River Basin, Indonesia, using predicted and measured concentrations. Sci Total Environ 738:140130-140130

40. Uwizeyimana H, Wang M, Chen W, Khan K (2017) The eco-toxic effects of pesticide and heavy metal mixtures towards earthworms in soil. Environ Toxicol Pharmacol 55:20-29

41. Wang K, Pang S, Mu X, Qi S, Li D, Cui F, Wang C (2015a) Biological response of earthworm, Eisenia fetida, to five neonicotinoid insecticides. Chemosphere 132:120-126

42. Wang Y, Chen C, Qian Y, Zhao X, Wang Q (2015b) Ternary toxicological interactions of insecticides, herbicides, and a heavy metal on the earthworm Eisenia fetida. J Hazard Mater 284:233-240

43. Woodcock BA, Bullock JM, Shore RF, Heard MS, Pereira MG, Redhead J, Ridding L, Dean H, Sleep D, Henrys P, Peyton J, Hulmes S, Hulmes L, Sarospataki M, Saure C, Edwards M, Genersch E, Knaebe S, Pywell RF (2017) Country-specific effects of neonicotinoid pesticides on honey bees and wild bees. Science 356:1393-1393+

44. Worek F, Eyer P, Thiermann H (2012) Determination of acetylcholinesterase activity by the Ellman assay: A versatile tool for in vitro research on medical countermeasures against organophosphate poisoning. Drug Testing Analysis 4:282-291

45. Xu B, Xue R, Zhou J, Wen X, Shi Z, Chen M, Xin F, Zhang W, Dong W, Jiang M (2020) Characterization of Acetamiprid Biodegradation by the Microbial Consortium ACE-3 Enriched From Contaminated Soil. Frontiers in Microbiology 11

46. Xusheng S, Zewen L, Xiaoyong X, Zhong L, Xuhong Q (2013) Overall status of neonicotinoid insecticides in China: Production, application and innovation. Journal of Pesticide Science 38:1-9

47. Yang G, Chen Yu, Yijun, Zhao H, Wen W, Yanhua (2018) Combined effects of four pesticides and heavy metal chromium $(\mathrm{VI})$ on the earthworm using avoidance behavior as an endpoint. Ecotoxicology \& Environmental Safety

48. Zhou Y, Guo J, Wang Z, Zhang B, Sun Z, Yun X, Zhang J (2020) Levels and inhalation health risk of neonicotinoid insecticides in fine particulate matter (PM2.5) in urban and rural areas of China. Environment International 142

\section{Figures}



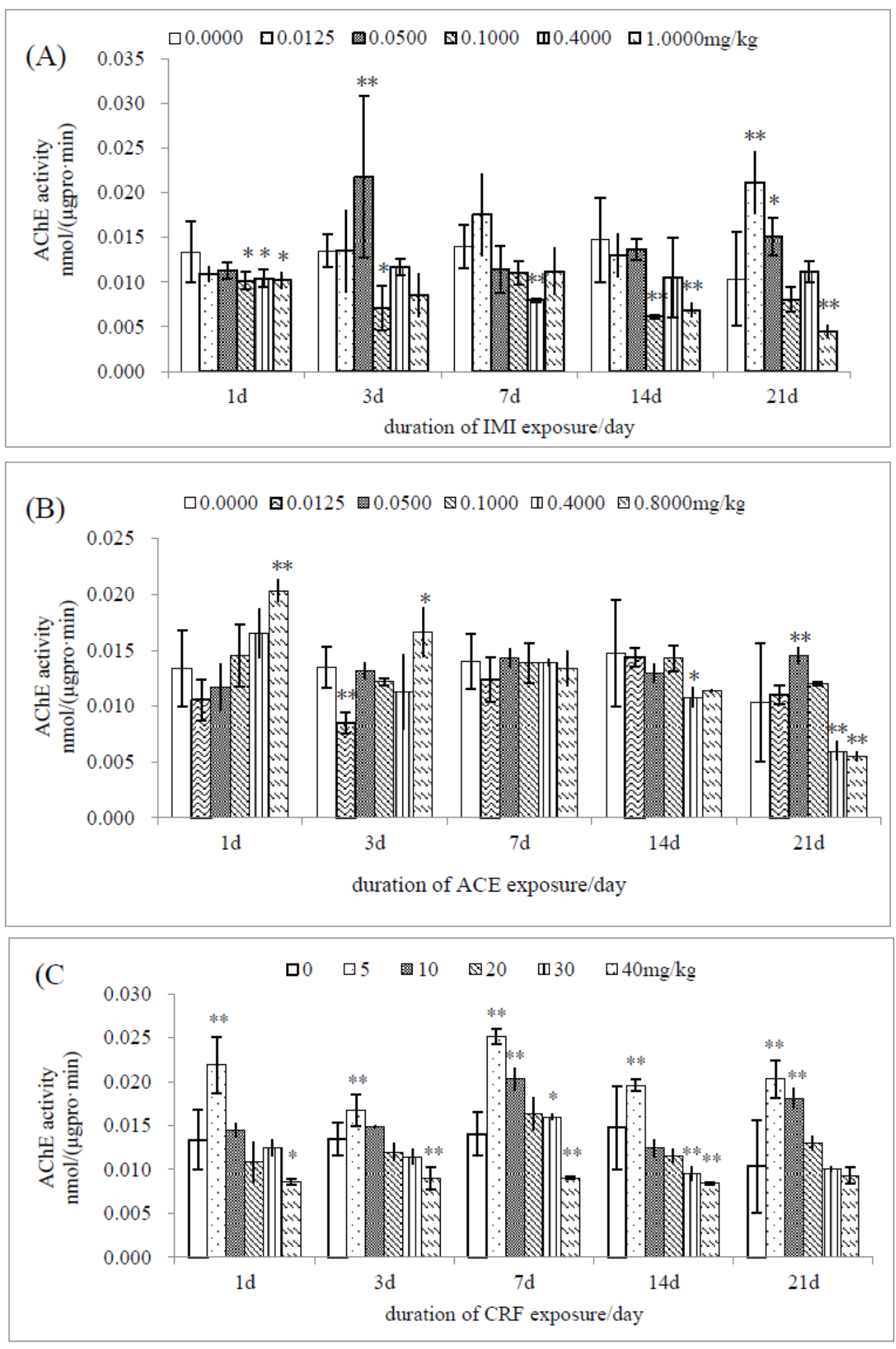

\section{Figure 1}

Acetylcholinesterase (AChE) activity in earthworm exposed to different concentrations of imidacloprid (IMI) (A), acetamiprid (ACE) (B), and chlorpyrifos (CRF) (C). Significant differences were assessed using a one-way ANOVA followed by Dunnett's test $\left({ }^{*} P<0.05,{ }^{\star *} P<0.01\right)$. Results are shown as mean \pm standard deviation (S.D.) values. 

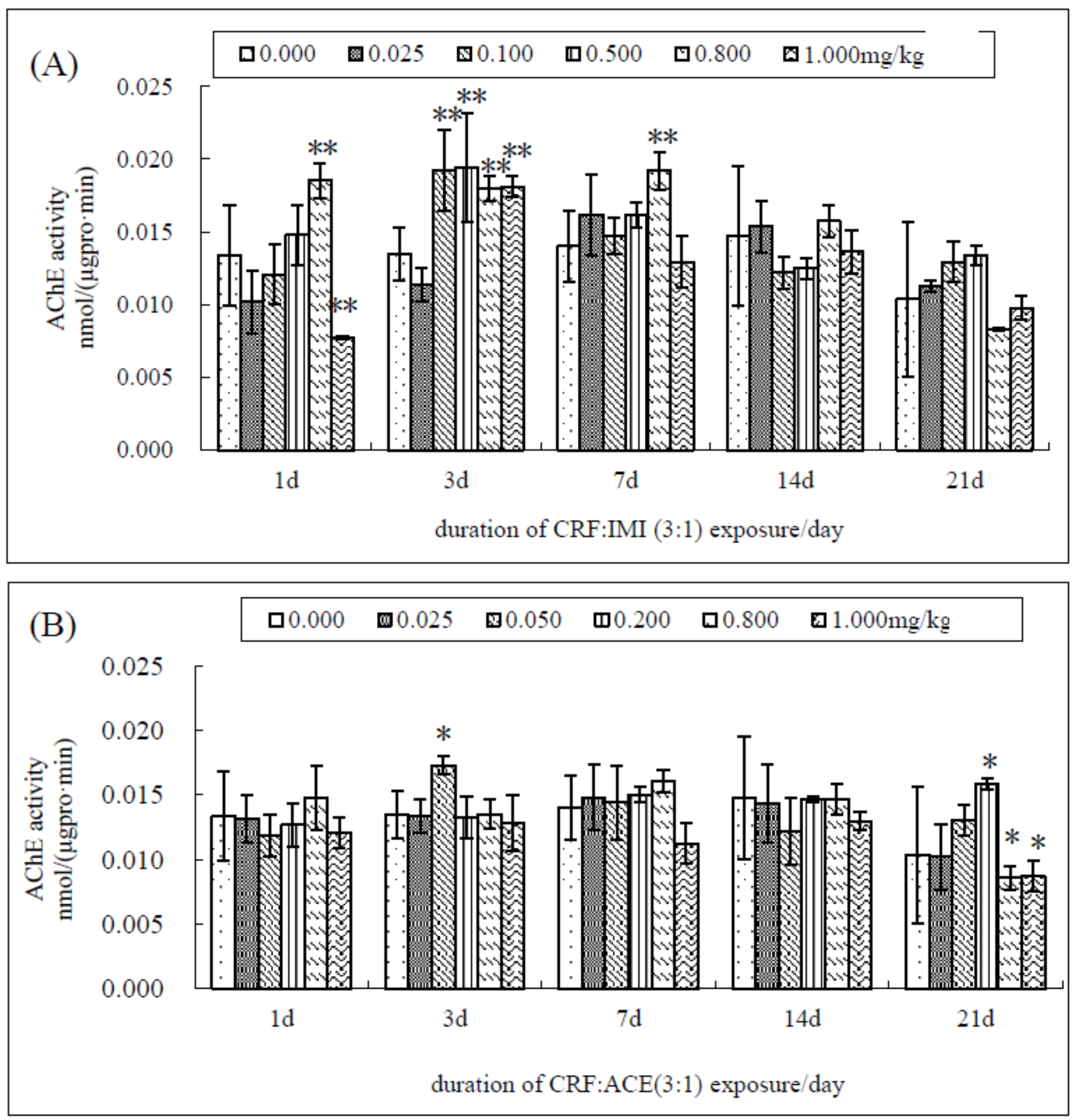

Figure 2

Acetylcholinesterase (AChE) activity in earthworms exposed to different concentrations of 3:1 mixtures of chlorpyrifos (CRF) with imidacloprid (IMI) (A) and acetamiprid (ACE) (B). Significant differences were assessed using a one-way ANOVA with Dunnett's test $\left({ }^{\star} P<0.05,{ }^{\star *} \mathrm{P}<0.01\right)$. Results are presented as mean \pm standard deviation (S.D.) values. 

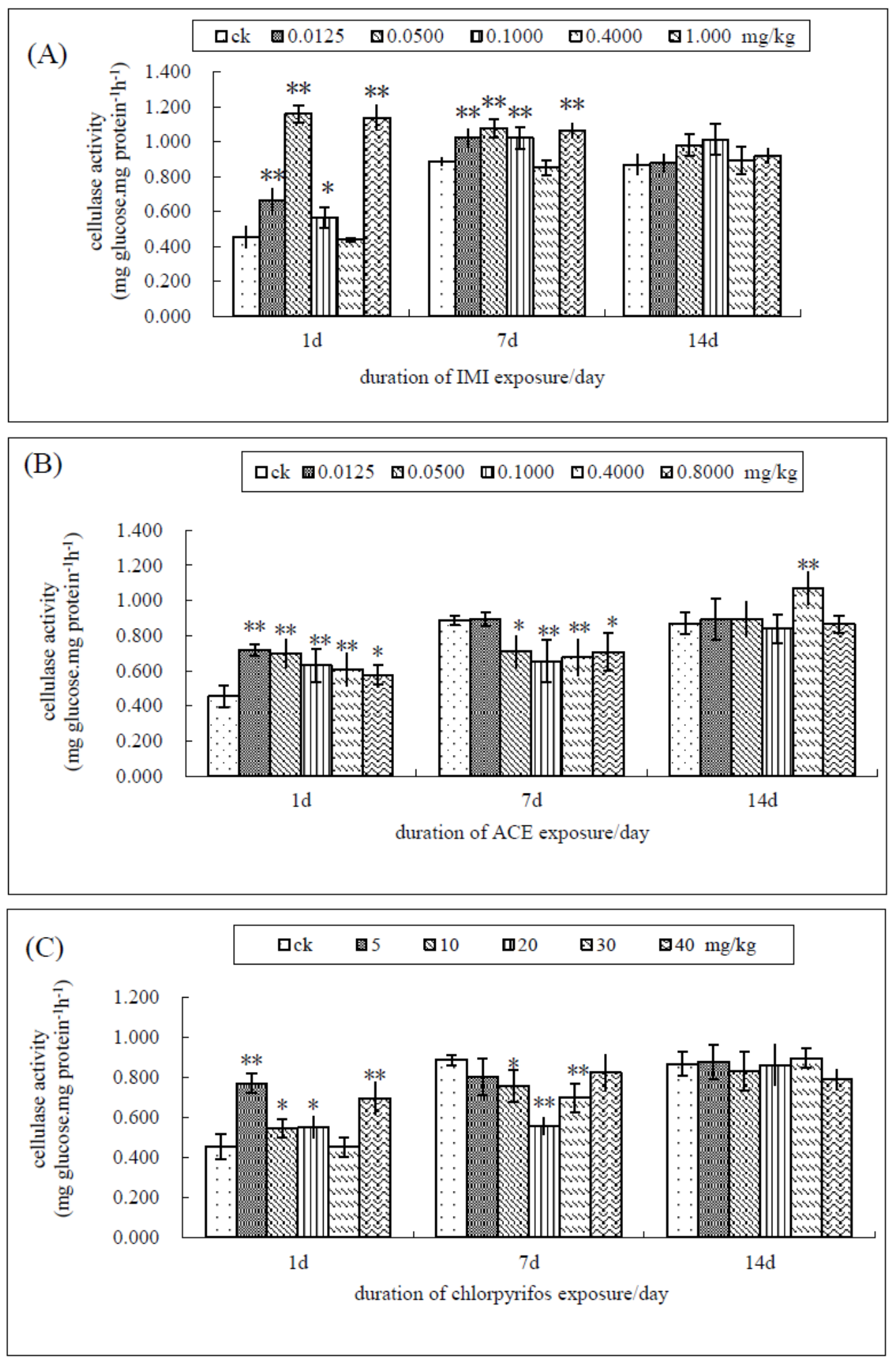

\section{Figure 3}

Cellulase activity in earthworms exposed to different concentrations of imidacloprid (IMI) (A), acetamiprid (ACE) (B), and chlorpyrifos (CRF) (C). Significant differences were assessed using a one-way ANOVA followed by Dunnett's test $\left({ }^{*} \mathrm{P}<0.05,{ }^{\star *} \mathrm{P}<0.01\right)$. Results are presented as mean \pm standard deviation (S.D.) values. 
(A)

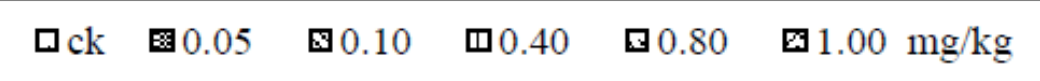

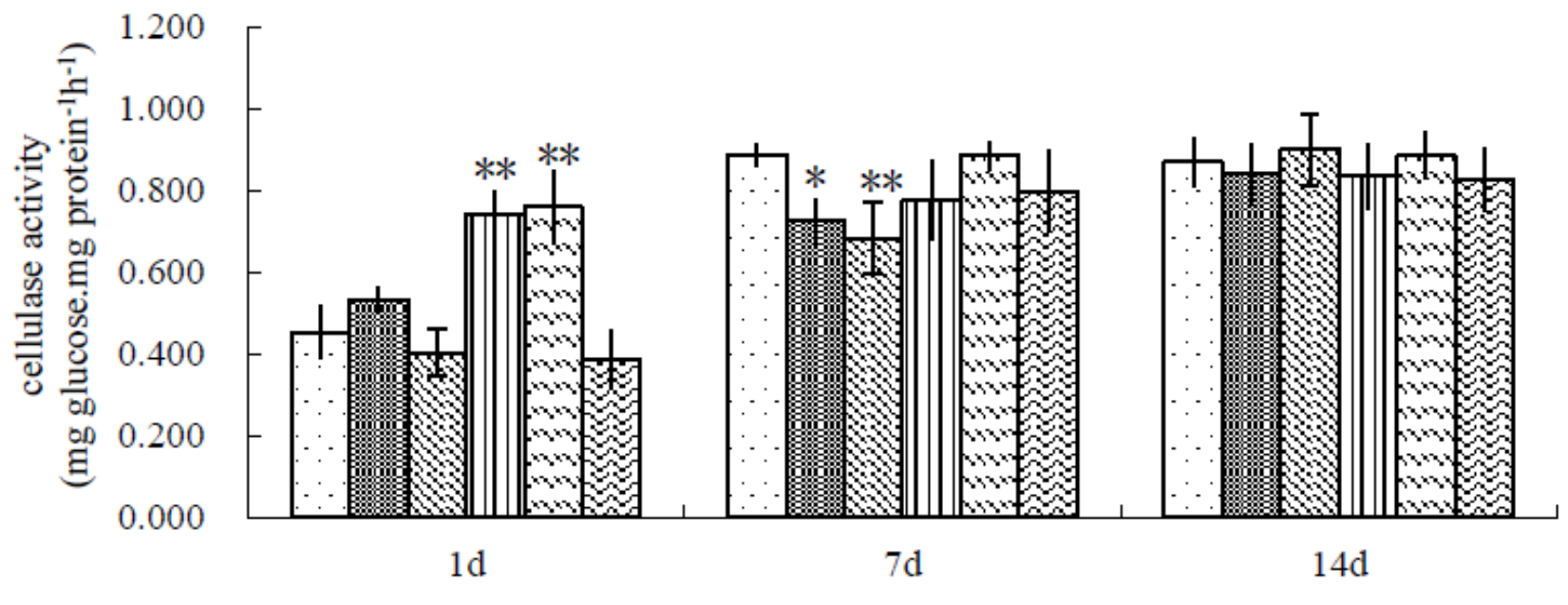

duration of CRF:IMI (3:1) exposure/day

(B)

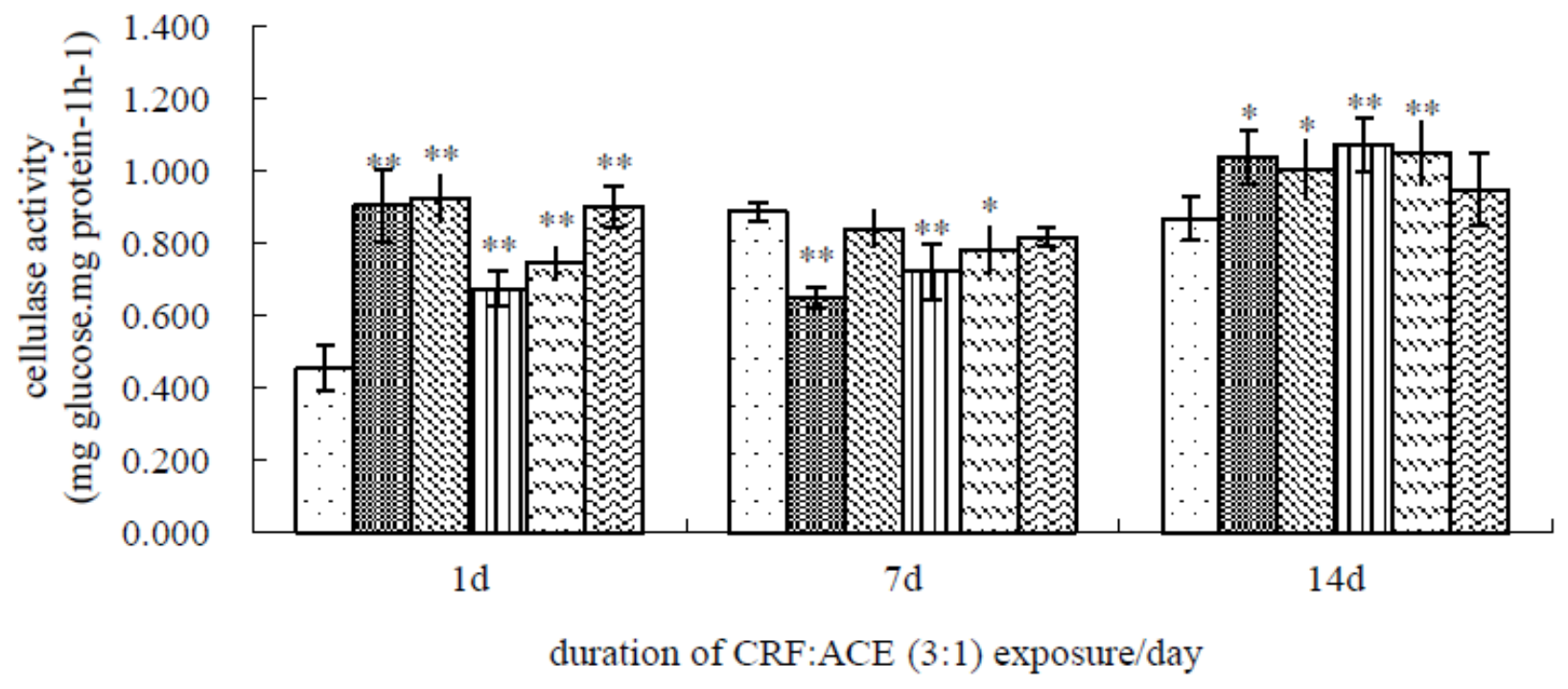

\section{Figure 4}

Cellulase activity of earthworms exposed to different concentrations of 3:1 mixtures of chlorpyrifos (CRF) with imidacloprid (IMI) (A) and acetamiprid (ACE) (B). Significant differences were assessed using a oneway ANOVA followed by Dunnett's test $\left({ }^{*} \mathrm{P}<0.05,{ }^{\star} * \mathrm{P}<0.01\right)$. Results are presented as mean \pm standard deviation (S.D.) values. 


\section{Supplementary Files}

This is a list of supplementary files associated with this preprint. Click to download.

- GraphicalAbstract.png 